\title{
Reactive oxygen species mediate soft corals- derived sinuleptolide-induced antiproliferation and DNA damage in oral cancer cells
}

\author{
This article was published in the following Dove Press journal: \\ OncoTargets and Therapy \\ 4 July 2017 \\ Number of times this article has been viewed
}

Yung-Ting Chang, ${ }^{1,2, *}$ ChiungYao Huang, ${ }^{3, *}$ Jen-Yang Tang, ${ }^{4,5}$ Chih-Chuang Liaw, ${ }^{1,3}$ RueiNian Li, ${ }^{6}$ Jing-Ru Liu, ${ }^{6}$ JyhHorng Sheu, ${ }^{1,3,7,8}$ Hsueh-Wei Chang,9-12

'Doctoral Degree Program in Marine Biotechnology, National Sun Yat-sen University, Kaohsiung, Taiwan; ${ }^{2}$ Doctoral Degree Program in Marine Biotechnology, Academia Sinica, Taipei, Taiwan; ${ }^{3}$ Department of Marine Biotechnology and Resources, National Sun Yat-sen University, Kaohsiung, Taiwan; ${ }^{4}$ Department of Radiation Oncology, Faculty of Medicine, College of Medicine, Kaohsiung Medical University, Kaohsiung, Taiwan; ${ }^{5}$ Department of Radiation Oncology, Kaohsiung Municipal Ta-Tung Hospital,

Kaohsiung, Taiwan; ${ }^{6}$ Department of Biomedical Science and Environmental Biology, Kaohsiung Medical University, Kaohsiung, Taiwan; ${ }^{7}$ Department of Medical Research, China Medical University Hospital, China Medical University, Taichung, Taiwan; ${ }^{8}$ Frontier Cente for Ocean Science and Technology, National Sun Yat-sen University, Kaohsiung, Taiwan; 'Institute of Medical Science and Technology, National Sun Yat-sen University, Kaohsiung, Taiwan; ${ }^{10}$ Cancer Center, Kaohsiung Medical University Hospital; Kaohsiung Medical University, Kaohsiung, Taiwan; "'Department of Medical Research, Kaohsiung Medical University Hospital, Kaohsiung, Taiwan; ${ }^{12}$ Research Center for Natural Products and Drug Development, Kaohsiung Medical University, Kaohsiung, Taiwan

*These authors contributed equally to this work

Correspondence: Jyh-Horng Sheu Department of Marine Biotechnology and Resources, National Sun Yat-sen University, 70, Lianhai Road, Kaohsiung 80424, Taiwan

Email sheu@mail.nsysu.edu.tw

Hsueh-Wei Chang

Department of Biomedical Science and Environmental Biology, Kaohsiung Medical University, 100, Shih-chuan Ist Road, Kaohsiung 80708, Taiwan

Email changhw@kmu.edu.tw
Abstract: We previously reported that the soft coral-derived bioactive substance, sinuleptolide, can inhibit the proliferation of oral cancer cells in association with oxidative stress. The functional role of oxidative stress in the cell-killing effect of sinuleptolide on oral cancer cells was not investigated as yet. To address this question, we introduced the reactive oxygen species (ROS) scavenger ( $N$-acetylcysteine [NAC]) in a pretreatment to evaluate the sinuleptolide-induced changes to cell viability, morphology, intracellular ROS, mitochondrial superoxide, apoptosis, and DNA damage of oral cancer cells (Ca9-22). After sinuleptolide treatment, antiproliferation, apoptosis-like morphology, ROS/mitochondrial superoxide generation, annexin V-based apoptosis, and $\gamma \mathrm{H} 2 \mathrm{AX}$-based DNA damage were induced. All these changes were blocked by NAC pretreatment at $4 \mathrm{mM}$ for $1 \mathrm{~h}$. This showed that the cell-killing mechanism of oral cancer cells of sinuleptolide is ROS dependent.

Keywords: soft corals, oral cancer, $N$-acetylcysteine, oxidative stress, $\gamma \mathrm{H} 2 \mathrm{AX}$

\section{Introduction}

Oral cancer is the sixth most prevalent form of cancer worldwide. ${ }^{1,2}$ Treatment options for oral cancer include surgery and chemotherapy. Several clinically approved drugs such as cisplatin are getting ineffective due to drug resistance in oral cancer therapy. ${ }^{3}$ Therefore, the discovery of new anti-oral cancer drugs becomes a challenging task.

Marine microbes, flora, and fauna provide promising sources of bioactive natural products, and they are used to develop well-received anticancer drugs. ${ }^{46}$ For example, peptides and roe protein hydrolysates derived from marine fish have been reported to inhibit the proliferation of oral cancer cells. ${ }^{7}$ The methanolic extract of red alga Gracilaria tenuistipitata was found to inhibit oral cancer cell proliferation. ${ }^{8}$ Luminacin, a marine microbial extract, was reported to induce autophagy and cell death in head and neck cancer cells. ${ }^{9}$ Accordingly, marine resources feature abundant natural marine products with potential anticancer effects.

Recently, many soft coral-derived compounds have been reported as having potential applications as anticancer drugs. ${ }^{10,11}$ Studies have investigated Sinularia lochmodes-derived sinuleptolide for marine natural product identification ${ }^{12}$ and for use in treating inflammation ${ }^{13}$ and skin cancer. ${ }^{14}$ The structure of sinuleptolide was first derived from the soft coral Sinularia sp. ${ }^{15}$ Alternatively, sinuleptolide was extracted from the soft corals Sinularia leptoclados and S. lochmodes in our laboratory. ${ }^{16,17}$ However, few studies have investigated the effects of sinuleptolide in the treatment of oral cancer. 
In our recent study, ${ }^{18}$ we reported that oxidative stress was associated with the sinuleptolide-induced killing of oral cancer cells. However, the dependence of oxidative stress in the cell-killing effect of sinuleptolide on oral cancer cells was not investigated. $N$-acetylcysteine (NAC), a glutathione precursor for replenishing cellular glutathione storage, is a well-known reactive oxygen species (ROS) scavenger. ${ }^{19}$ NAC pretreatment can be used to investigate the role of oxidative stress dependence in drug and natural productmediated cancer cell death. ${ }^{20-23}$ Therefore, the purpose of this study is to evaluate the role of oxidative stress in the cellkilling effects of sinuleptolide against oral cancer cells.

\section{Materials and methods Cell cultures and chemicals}

Human oral cancer cells (Ca9-22), purchased from the Health Science Research Resources Bank (HSRRB) (Osaka, Japan), were incubated with DMEM medium (Gibco, Grand Island, NY, USA) and fetal bovine serum. ${ }^{24}$ Human normal gingival fibroblast cells (HGF-1), purchased from the American Type Culture Collection (ATCC; Manassas, VA, USA), were incubated with DMEM-F12 medium (Gibco, Grand Island, NY, USA). ${ }^{25}$ These cells were maintained at $37^{\circ} \mathrm{C}$ in a humidified $5 \% \mathrm{CO}_{2}$ atmosphere. The structure and preparation of soft corals Sinularia-derived sinuleptolide was isolated from $S$. lochmodes as described in our previous study. ${ }^{17}$ It was freshly prepared in dimethyl sulfoxide (DMSO) for cell studies. All the DMSO concentrations of sinuleptolide treatments were unified at $0.24 \%$. NAC (Sigma, St Louis, MO, USA) was pretreated with $4 \mathrm{mM}$ for $1 \mathrm{~h}$ before sinuleptolide treatment.

\section{Cell viability}

CellTiter $96^{\circledR}$ AQueous One Solution Cell Proliferation Assay (MTS) (Promega Corporation, Madison, WI, USA) was chosen to measure cell proliferation. ${ }^{24}$ After plating overnight, Ca9-22 cells were incubated with sinuleptolide for $24 \mathrm{~h}$ with or without NAC pretreatment. Finally, the MTS response was measured by an ELISA reader (EZ Read 400 Research Reader; BioChrom, Cambridge, UK).

\section{Intracellular ROS production}

Intracellular hydrogen peroxide or other oxidizing ROS can react with $2^{\prime}, 7^{\prime}$-dichlorodihydrofluorescein diacetate (DCFH-DA) and generate fluorescence. ${ }^{26,27}$ The ROS level can be detected using flow cytometry. ${ }^{8}$ In brief, after plating overnight, Ca9-22 cells were incubated with sinuleptolide for $3 \mathrm{~h}$ with or without NAC pretreatment. After washing with PBS, cells were incubated with $100 \mathrm{nM}$ DCFH-DA in PBS at $37^{\circ} \mathrm{C}$ for $30 \mathrm{~min}$. After harvesting, cells were resuspended in $1 \mathrm{~mL}$ PBS for flow cytometry analysis (BD Accuri ${ }^{\mathrm{TM}} \mathrm{C} 6$; Becton, Dickinson and Company, Franklin Lakes, NJ, USA). Mean intensity of ROS was collected from $1 \times 10^{4}$ cell counts.

\section{Mitochondrial superoxide production}

The mitochondrial superoxide was reacted with MitoSOX ${ }^{\mathrm{TM}}$ Red (Molecular Probes; Invitrogen, Eugene, OR, USA) and generated fluorescence. ${ }^{28}$ MitoSOX Red was also applied to flow cytometry. ${ }^{18}$ In brief, after plating overnight, Ca9-22 cells were incubated with sinuleptolide for $1 \mathrm{~h}$ with or without NAC pretreatment. Subsequently, cells were incubated with $5 \mu \mathrm{M}$ MitoSOX $37^{\circ} \mathrm{C}$ for $30 \mathrm{~min}$. After harvesting, cells were resuspended in $1 \mathrm{~mL}$ PBS for flow cytometer analysis (BD Accuri (6). Mean intensity of mitochondrial superoxide was collected from $1 \times 10^{4}$ cell counts.

\section{DNA damage by $\gamma \mathrm{H} 2 \mathrm{AX} /$ propidium iodide}

$\gamma \mathrm{H} 2 \mathrm{AX}$ is the marker of DNA double-strand breaks, and it can be detected by flow cytometry. ${ }^{24}$ In brief, sinuleptolidetreated cells were fixed in 70\% ethanol. After washing with BSA-T-PBS solution ( $1 \%$ bovine serum albumin and $0.2 \%$ Triton X-100 in PBS; Sigma), cells were incubated with p-Histone H2A.X (Ser 139) monoclonal antibody (Santa Cruz Biotechnology, Santa Cruz, CA, USA) and BSA-T-PBS buffer in 1:50 dilution at $4^{\circ} \mathrm{C}$ for $1 \mathrm{~h}$. After washing, Alexa Fluor 488-tagged secondary antibody (Jackson Laboratory, Bar Harbor, ME, USA) with BSA-T-PBS buffer in a 1:50 dilution was added for $30 \mathrm{~min}$ at room temperature. After the addition of $20 \mu \mathrm{g} / \mathrm{mL}$ of propidium iodide (PI), cells were resuspended for flow cytometry analysis (BD Accuri C6). Mean intensity of $\gamma \mathrm{H} 2 \mathrm{AX}$ was collected from $1 \times 10^{4}$ cell counts.

\section{Statistical analysis}

Experimental data were analyzed and expressed as mean \pm SD. Data were analyzed using two-sample Student's $t$-test with Bonferroni correction. The $P$-values $<0.01(=0.05 / 5)$ are considered as statistically significant.

\section{Results \\ NAC effect on sinuleptolide-induced cell killing}

In the MTS assay (Figure 1A and B), sinuleptolide concentration responsively decreased the cell viability (\%) of 
A

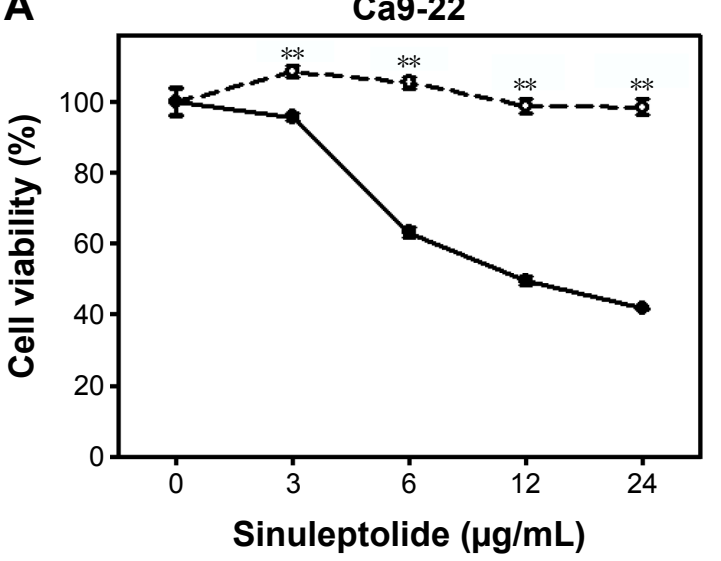

B

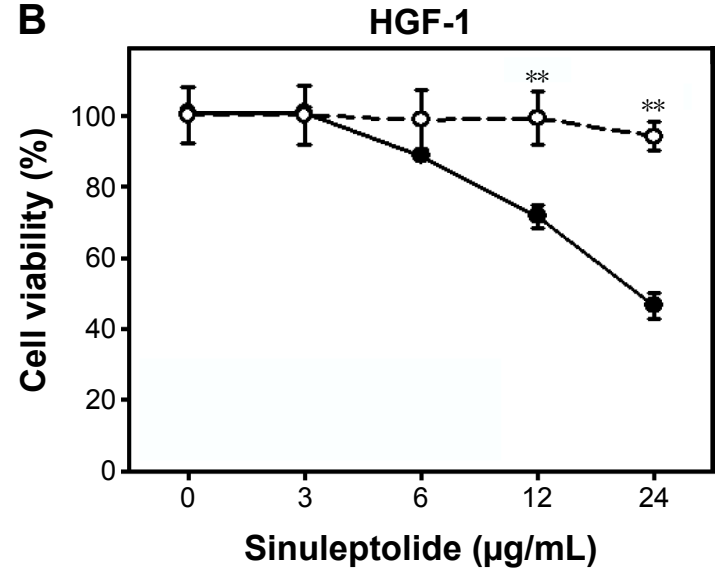

-๑- NAC + sinuleptolide $\rightarrow-$ Sinuleptolide

Figure I NAC effect on cell viabilities of sinuleptolide-treated oral cancer and normal cells.

Notes: (A) Cell viabilities of oral cancer cells. (B) Cell viabilities of oral normal cells. With or without $4 \mathrm{mM}$ NAC pretreatment for I h, oral cancer cells (Ca9-22) or oral normal cells (HGF-I) were incubated with $3,6,12$, and $24 \mu \mathrm{g} / \mathrm{mL}$ of sinuleptolide for $24 \mathrm{~h}$. Cell viability was measured by the MTS assay. Data, mean \pm SD ( $=6$ ). $* * P$-value of $<0.002$ for the significance between data with or without NAC pretreatment.

Abbreviation: NAC, N-acetylcysteine.

oral cancer cells (Ca9-22) and oral normal cells (HGF-1), but sinuleptolide selectively killed $\mathrm{Ca} 9-22$ cells and was less harmful to HGF-1 cells, which was consistent with our previous study. ${ }^{18} \mathrm{The} \mathrm{IC}_{50}$ values of sinuleptolide in Ca9-22 and HGF-1 cells were 11.76 and $22.3 \mu \mathrm{g} / \mathrm{mL}$, respectively. As NAC is a common ROS scavenger, ${ }^{29,30}$ this NAC effect was used in the present study to address the dependence of oxidative stress for the sinuleptolide effect on oral cancer compared with normal cells. We found that the sinuleptolide (3-24 $\mu \mathrm{g} / \mathrm{mL}$ )-induced cell killing in Ca9-22 and HGF-1 cells was significantly reduced by a pretreatment with NAC $(P<0.002)$ (Figure 1A and B).

\section{NAC effect on sinuleptolide-induced morphology change}

The cell morphology was changed and became more abnormal in sinuleptolide-treated oral cancer cells (Ca9-22) (Figure 2A) than in HGF-1 cells (Figure 2B). At higher concentrations of sinuleptolide (12 and $24 \mu \mathrm{g} / \mathrm{mL})$, apoptosis-like morphological changes, such as apoptotic
A
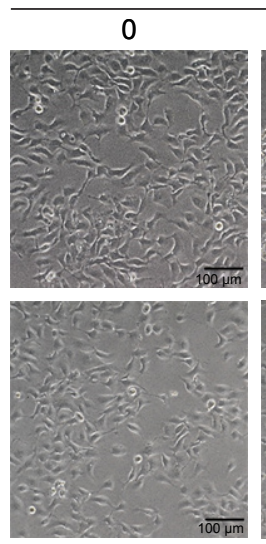

Ca9-22
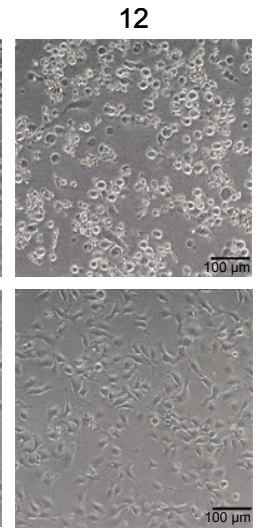

B
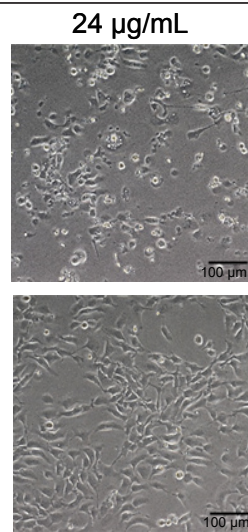
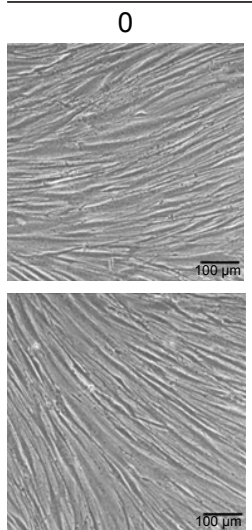

HGF-1
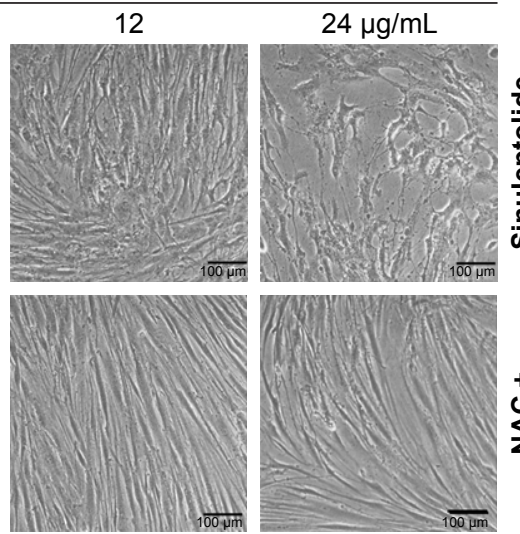

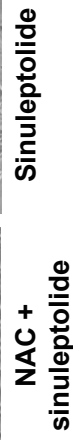

Figure 2 NAC effect on cell morphology of sinuleptolide-treated oral cancer and oral normal cells.

Notes: NAC pretreatment condition was $4 \mathrm{mM}$ for I h. No NAC pretreatment was kept in culture medium for I h. Cells were incubated with 0 , 3, 6 , 12 , and $24 \mu \mathrm{g} / \mathrm{mL}$ of sinuleptolide for $24 \mathrm{~h}$. (A and B) Cell morphology of sinuleptolide-treated oral cancer cells (Ca9-22) and oral normal cells (HGF-I). Cell morphology was observed under $100 \times$ magnification (scale bar is $100 \mu \mathrm{m}$ ).

Abbreviation: NAC, $\mathrm{N}$-acetylcysteine. 
bodies and cell shrinkages, were observed in Ca9-22 cells. However, these sinuleptolide-induced apoptosislike or abnormal morphologies were reduced by NAC pretreatment.

\section{NAC effect on the sinuleptolide-induced ROS generation}

Figure $3 \mathrm{~A}$ and $\mathrm{B}$ shows the relative ROS intensity patterns of sinuleptolide-induced ROS generation of Ca9-22 and HGF-1 cells with or without NAC pretreatment. At higher concentrations of sinuleptolide ( 12 and $24 \mu \mathrm{g} / \mathrm{mL}$ ) (Figure 3C), the ROS generation of Ca9-22 cells was upregulated, which was consistent with the results of our previous study. ${ }^{18}$ After NAC pretreatment, the sinuleptolide-induced ROS generation of $\mathrm{Ca} 9-22$ cells was significantly reduced by NAC pretreatment $(P<0.002)$ (Figure $3 C)$. In contrast, the ROS generation of HGF-1 cells was maintained at a basal level with or without NAC pretreatment (Figure 3D).

\section{NAC effect on the generation of sinuleptolide-induced mitochondrial superoxide}

Mitochondria-specific ROS staining dye (MitoSOX Red) was used to evaluate mitochondrial superoxide by flow cytometry. Figure $4 \mathrm{~A}$ and $\mathrm{B}$ shows the relative mitochondrial superoxide intensity patterns of NAC pretreatment effects against sinuleptolide-treated oral cancer and normal cells. Higher concentrations of sinuleptolide (12 and $24 \mu \mathrm{g} / \mathrm{mL}$ ) (Figure $4 \mathrm{C}$ and $\mathrm{D}$ ) induced the mitochondrial superoxide generation of Ca9-22 and HGF-1 cells. NAC pretreatment significantly reduced the sinuleptolide-induced mitochondrial superoxide generation of Ca9-22 and HGF-1 cells $(P<0.002)$.

\section{NAC effect on sinuleptolide-induced $\gamma \mathrm{H} 2 \mathrm{AX} / \mathrm{PI}$-based DNA damage}

Figure $5 \mathrm{~A}$ and $\mathrm{B}$ shows the relative $\gamma \mathrm{H} 2 \mathrm{AX}$ intensity patterns of sinuleptolide-induced DNA damage in Ca9-22 and
A

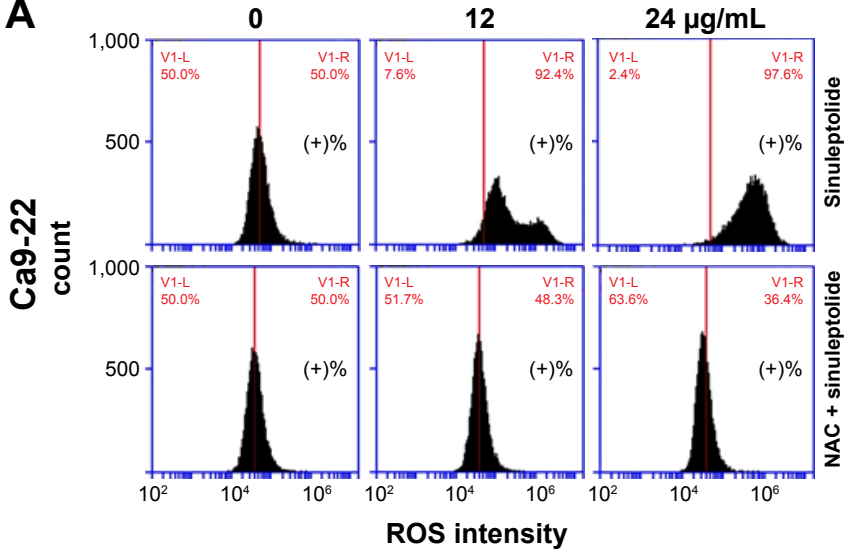

B

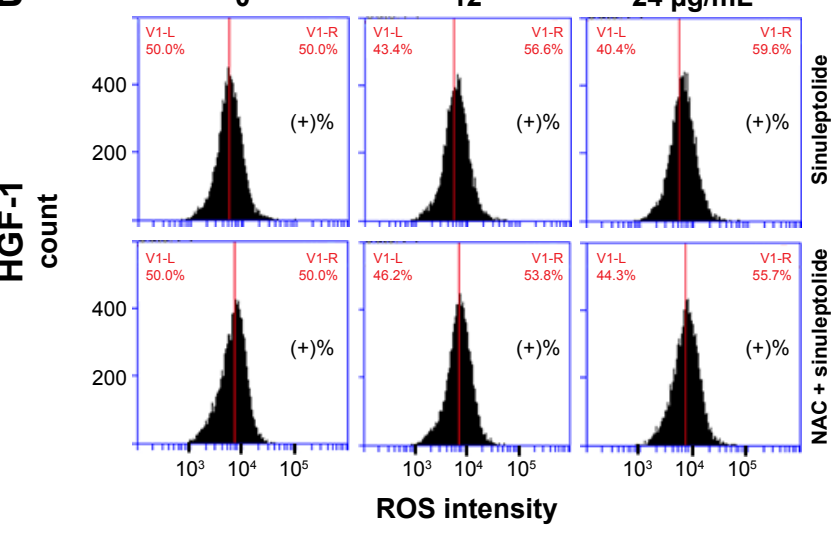

C $\quad$ Ca9-22

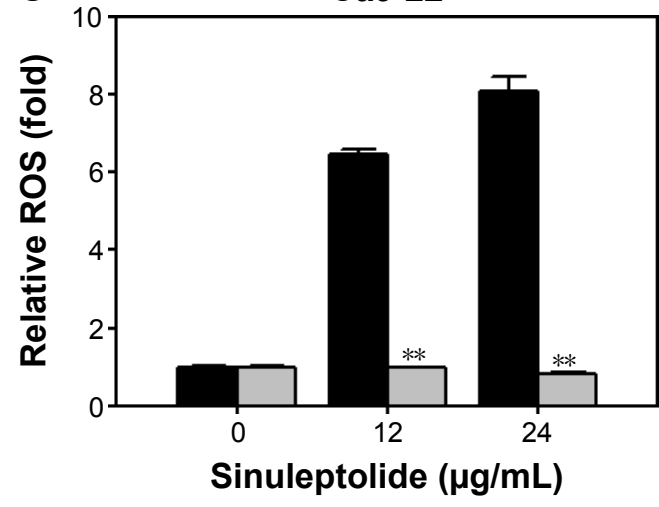

D HGF-1

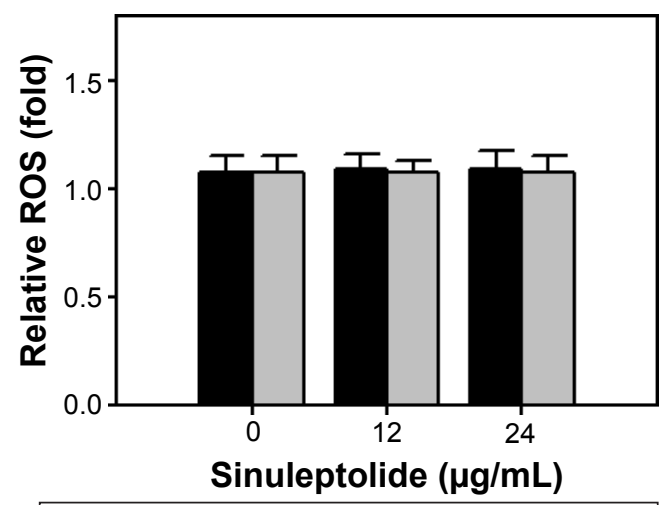

Sinuleptolide $\square$ NAC + sinuleptolide

Figure 3 NAC effect on ROS generation of sinuleptolide-treated oral cancer cells and oral normal cells.

Notes: NAC pretreatment condition was $4 \mathrm{mM}$ for I h. No NAC pretreatment was kept in culture medium for I h. Oral cancer cells (Ca9-22) were incubated with 0, I2, and $24 \mu \mathrm{g} / \mathrm{mL}$ of sinuleptolide for $6 \mathrm{~h}$. (A and B) Typical ROS patterns of sinuleptolide treated Ca9-22 and HGF-I cells. The right side of each flow cytometry panel indicates the ROS positive (+\%) region. (C and D) Statistics of relative mean intensity of ROS pattern (in $\mathbf{A}$ and $\mathbf{B}$ ). Data, mean $\pm S D$ ( $n=3$ ). $* * P$-value of $<0.002$ for the significance between data with or without NAC pretreatment.

Abbreviations: NAC, $\mathrm{N}$-acetylcysteine; ROS, reactive oxygen species. 
A

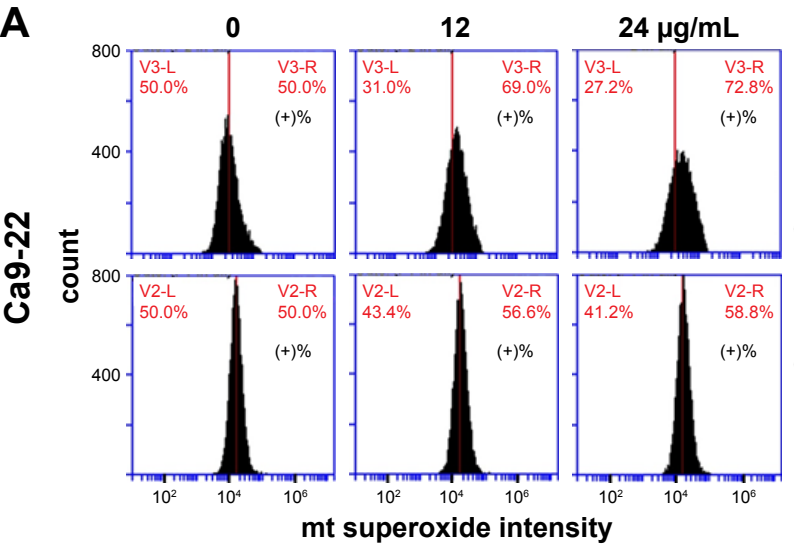

B

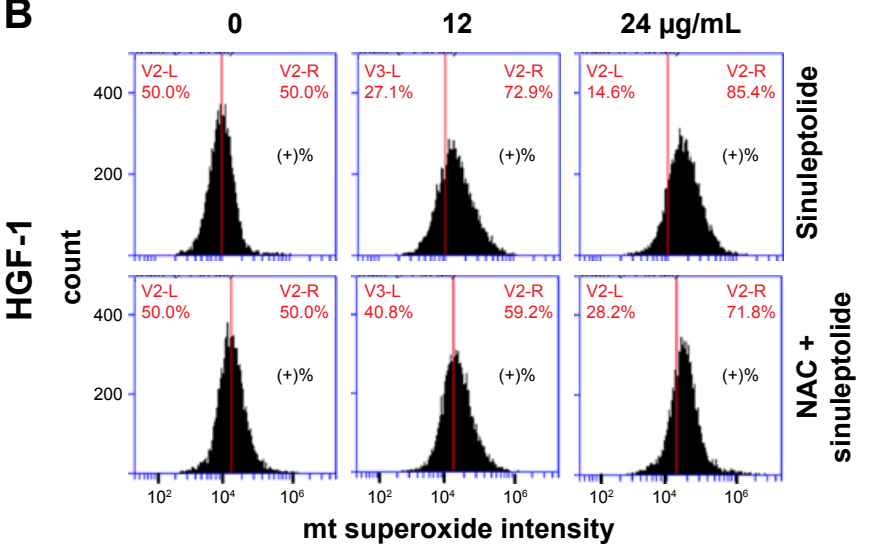

C

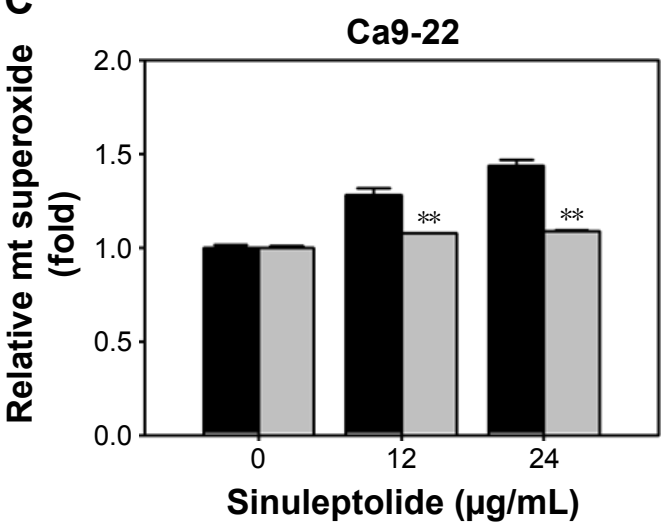

D

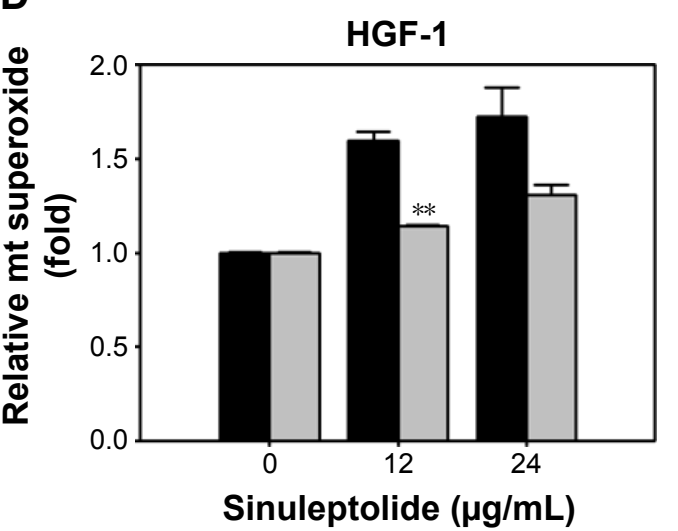

Sinuleptolide $(\mu \mathrm{g} / \mathrm{mL})$

Figure 4 NAC effect on mitochondrial $(\mathrm{mt})$ superoxide generation of sinuleptolide-treated oral cancer cells.

Notes: NAC pretreatment condition was $4 \mathrm{mM}$ for I h. No NAC pretreatment was kept in culture medium for I h. Oral cancer cells (Ca9-22) were incubated with 0, I2, and $24 \mu \mathrm{g} / \mathrm{mL}$ of sinuleptolide for I h. (A and B) Typical mt superoxide patterns of sinuleptolide treated Ca9-22 and HGF-I cells. The right side of each flow cytometry panel indicates the $\mathrm{mt}$ superoxide positive $(+\%)$ region. $(\mathbf{C}$ and $\mathbf{D})$ Statistics of relative mean intensity of $\mathrm{mt}$ superoxide pattern (in $\mathbf{A}$ and $\mathbf{B})$. Data, mean $\pm \mathrm{SD}\left(\mathrm{n}=3\right.$ ). ${ }^{* * P} \mathrm{P}$-value of $<0.002$ for the significance between data with or without NAC pretreatment.

Abbreviation: NAC, $\mathrm{N}$-acetylcysteine.

HGF-1 cells with or without NAC pretreatment. The higher concentrations of sinuleptolide (12 and $24 \mu \mathrm{g} / \mathrm{mL}$ ) (Figure 5C) dramatically induced the $\gamma \mathrm{H} 2 \mathrm{AX}$ expression of $\mathrm{Ca} 9-22$ cells, which was consistent with our previous study. ${ }^{18}$ After NAC pretreatment, the sinuleptolide-induced $\gamma \mathrm{H} 2 \mathrm{AX}$ expression in $\mathrm{Ca} 9-22$ cells was significantly reduced by NAC pretreatment $(P<0.002)$. In contrast, sinuleptolide-induced $\gamma \mathrm{H} 2 \mathrm{AX}$ expression of HGF-1 cells was maintained at a basal level with or without NAC pretreatment (Figure 5D).

\section{Discussion}

We could show here that NAC pretreatment inhibited sinuleptolide-induced cell killing, apoptosis-like morphology, and apoptosis of oral cancer cells. This indicated the role of oxidative stress in the cytotoxicity provided by sinuleptolide for oral cancer cells. Moreover, oxidative stress is involved in early apoptosis ${ }^{31}$ and mitochondrial dysfunction. ${ }^{32-34} \mathrm{NAC}$ can interact with ROS, such as hydrogen peroxide, hydroxyl radical, superoxide, and hypochlorous acid. ${ }^{35}$ Consistently, we also found that NAC pretreatment inhibited sinuleptolideinduced ROS and the generation of mitochondrial superoxide. However, NAC is known to show other properties as well. For example, NAC also has anti-inflammatory effects. ${ }^{36-38}$ Since our study lacks experiments to exclude this possibility, sinuleptolide-induced cytotoxicity of oral cancer cells may also include other than an "ROS-dependent" mechanism.

DCFH-DA is used to detect intracellular ROS such as hydrogen peroxide, but does not specifically detect mitochondrial ROS. In contrast, MitoSOX Red dye has been reported to selectively detect superoxide in the mitochondria of live cells rather than other ROS. ${ }^{39}$ The role of mitochondrial superoxide was first reported as being involved in sinuleptolide-induced cytotoxicity in the present study. However, sinuleptolide induces cell death in both kinds of cells with different $\mathrm{IC}_{50}$ values $(\mathrm{Ca} 9-22=11.76$ and $\mathrm{HGF}-1=22.3 \mu \mathrm{g} / \mathrm{mL})$. The reason for some differences only observed with ROS and DNA damage 
A

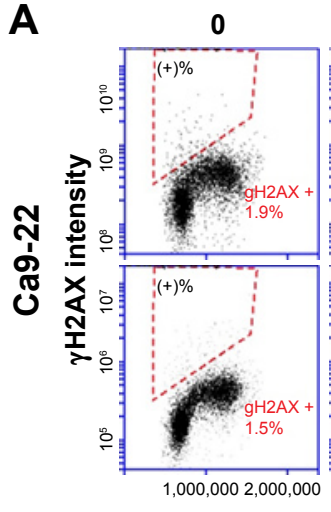

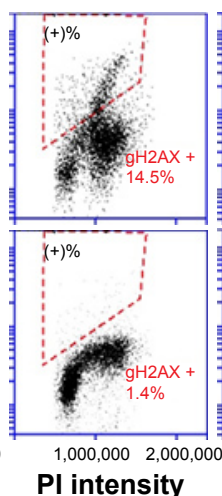

B
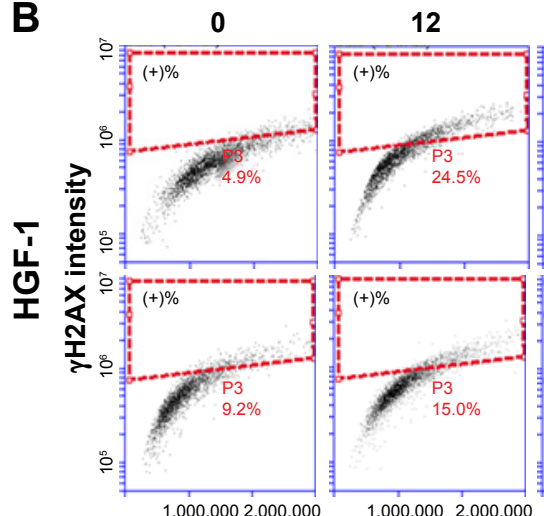

PI intensity
$24 \mu \mathrm{g} / \mathrm{mL}$

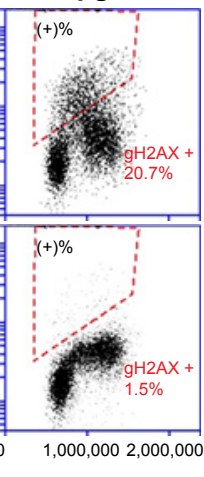

$24 \mu \mathrm{g} / \mathrm{mL}$

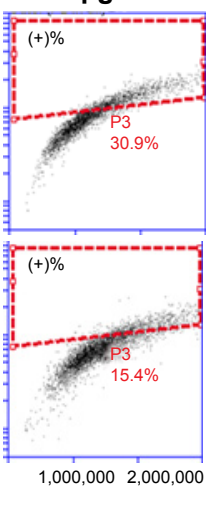

C

Ca9-22
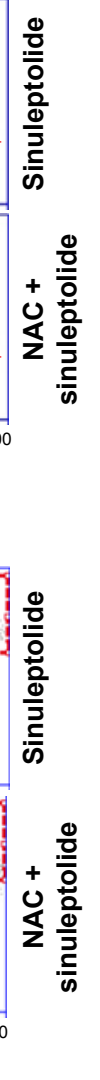

D
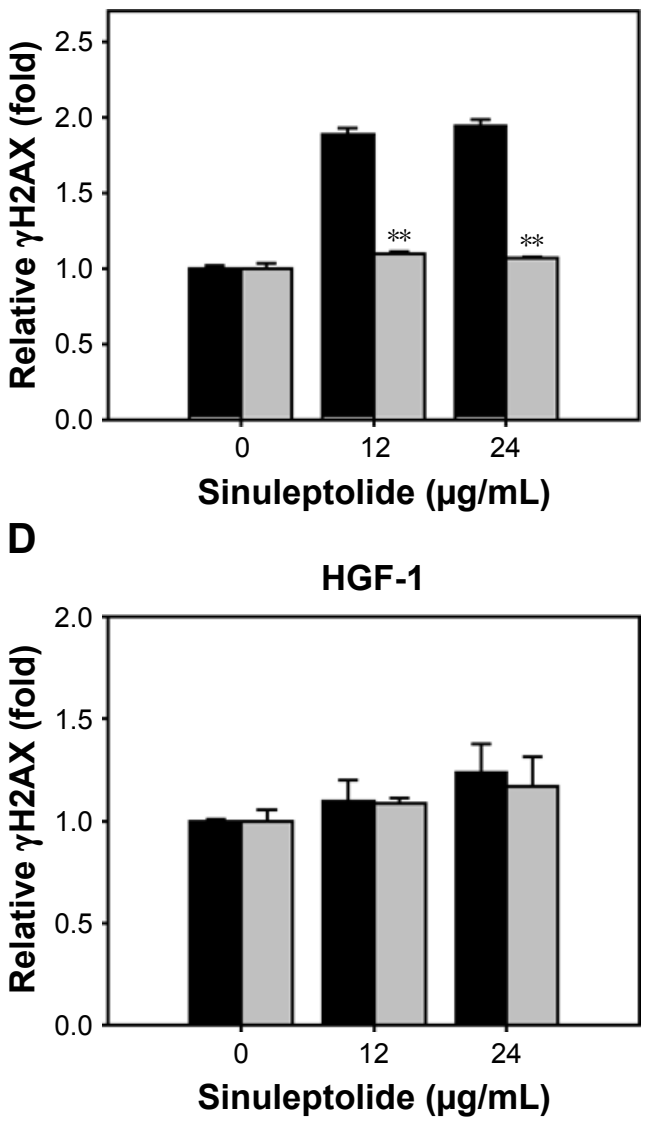

Sinuleptolide $\square$ NAC + sinuleptolide

Figure 5 NAC effect on $\gamma \mathrm{H} 2 \mathrm{AX}$-based DNA damage in sinuleptolide-treated oral cancer and oral normal cells.

Notes: NAC pretreatment condition was $4 \mathrm{mM}$ for I h. No NAC pretreatment was kept in culture medium for I h. Oral cancer cells (Ca9-22) were incubated with 0, 6, 12, and $24 \mu \mathrm{g} / \mathrm{mL}$ of sinuleptolide for $24 \mathrm{~h}$. (A and B) Typical $\gamma \mathrm{H} 2 \mathrm{AX}$ pattern of sinuleptolide-treated Ca9-22 and HGF-I cells. Dashed lines of each flow cytometry panel indicate the $\gamma \mathrm{H} 2 \mathrm{AX}$ positive (+\%) regions. ( $\mathbf{C}$ and $\mathbf{D})$ Statistics of mean intensity of $\gamma \mathrm{H} 2 \mathrm{AX}$-based DNA damage pattern (in $\mathbf{A}$ and $\mathbf{B}$ ). Data, mean $\pm \mathrm{SD}$ ( $\mathrm{n}=3$ ). ${ }^{* * P} \mathrm{P}$-value of $<0.002$ for the significance between data with or without NAC pretreatment.

Abbreviations: NAC, N-acetylcysteine; PI, propidium iodide.

in sinuleptolide-treated cells remains unclear as yet. One possibility is that mitochondrial and cytoplasmic ROS have diverse functions. For example, accumulating evidence suggests that mitochondrial ROS are important for normal cell functioning. ${ }^{40}$ Mitochondrial and cytoplasmic ROS may play opposing effects throughout the life cycle. For Caenorhabditis elegans, the increase of mitochondrial ROS increases the lifespan of this invertebrate, whereas the increase of cytoplasm ROS decreases its lifespan. ${ }^{41}$ However, the detailed function of mitochondrial and cytoplasmic ROS in sinuleptolide-induced cytotoxicity against cancer cells warrants further investigation.

p53 is reported to highly regulate redox homeostasis and to modulate several ROS-regulating genes. ${ }^{42}$ In contrast, ROS can modify $\mathrm{p} 53$ conformation to adjust the transcription of $\mathrm{p} 53 .{ }^{42}$ In the current study, ROS was validated to play an important role in sinuleptolide-induced cell death of oral cancer cells. However, the role of p53 in sinuleptolide-treated cells was not investigated in the current study. Furthermore, the status of p53 in Ca9-22 cells is a mutant form, ${ }^{43,44}$ but it is wild-type (wt) in the HGF-1 cells. Cells with mutant or wt p53 may display different responses. For example, hyperthermia induced apoptosis in oral squamous cell carcinoma (OSCC) cells (wt p53) and decreased IL-12 expression, but it increased IL-12R $\beta 1$ in OSCC (mutated p53). ${ }^{45}$ Accordingly, the role of p53 in sinuleptolide-induced antiproliferation and DNA damage effects of oral cancer cells warrants further investigation in the future.

Mitochondria are commonly assumed to have a tubular form in healthy cells, but donut or blob forms increased with mitochondrial superoxide, ${ }^{46}$ suggesting that mitochondrial shape may change at different conditions of mitochondrial ROS generation. The mitochondrial superoxide intensity increased upon oxidative stress with inhibitors of the mitochondrial complex I (rotenone) and mitochondrial complex II (antimycin). ${ }^{46} \mathrm{NAC}$ pretreatment has been reported 


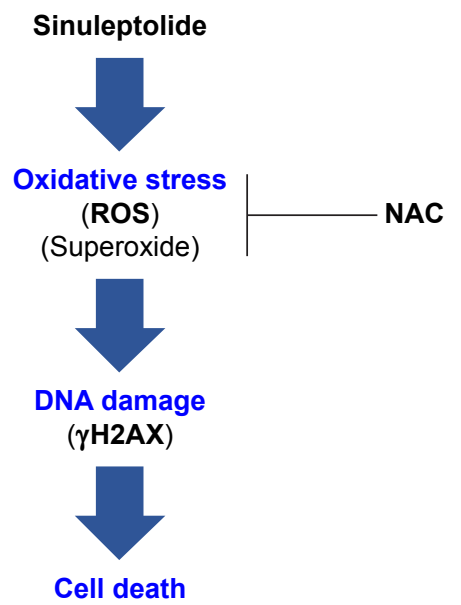

Figure 6 Overview of the hypothesized mechanism of sinuleptolide-induced killing of human oral cancer cells (Ca9-22) involving oxidative stress.

Notes: The role of oxidative stress was demonstrated by pretreatment with NAC that scavenges ROS and prevents mitochondrial superoxide generation. NAC consequently inhibits DNA damage and cell death.

Abbreviations: NAC, N-acetylcysteine; ROS, reactive oxygen species.

to reduce mitochondrial superoxide levels and mitochondrial donut or blob formations ${ }^{46}$ This suggests further investigation of sinuleptolide-induced mitochondrial shape change.

Moreover, oxidative stress commonly induces DNA damage, ${ }^{47}$ but we found that sinuleptolide-induced DNA damage was reduced by NAC pretreatment, suggesting that oxidative stress plays an important role in the DNA damaging effect of sinuleptolide in oral cancer cells. In addition, the sinuleptolide-induced DNA damage effect may have led to apoptosis in our previous study. ${ }^{18}$ Our preliminary result also found that sinuleptolide-induced apoptosis may be reduced by NAC pretreatment as indicated by the cleaved Poly (ADP-ribose) polymerase (PARP) assay (data not shown).

Some oxidative stress modulating drugs have been reported to modulate the endoplasmic reticulum (ER) stress provided by oxidative stress. ${ }^{48,49}$ ROS has also been reported to induce autophagy when exposed to nonmarine drugs and marine drugs. ${ }^{50}$ Because sinuleptolide-induced killing of oral cancer cells was shown to depend on oxidative stress, the possible responses of ER stress and autophagy in sinuleptolide-treated oral cancer cells warrant further investigation. Moreover, NAC was reported to inactivate c-Jun N-terminal kinase, p38 mitogen-activated protein kinase, activating protein-1, and nuclear factor kappa B. ${ }^{51}$ These kinase signaling proteins need to be further investigated in terms of the sinuleptolide mediation in the future.

\section{Conclusion}

In conclusion, we demonstrated that sinuleptolide induces cell killing, apoptosis, and DNA damage in oral cancer cells by allowing for relatively high cellular ROS levels.
This effect was significantly reduced by NAC pretreatment that allows ROS scavengers to reduce the actual ROS content (Figure 6). This suggests that the marine bioactive compound sinuleptolide kills oral cancer cells by mediating oxidative stress.

\section{Acknowledgments}

This work was supported by funds of the Ministry of Science and Technology (MOST 104-2320-B-037-013-MY3, MOST 104-2320-B-110-001-MY2, and MOST 105-2314-B-037036), the National Sun Yat-sen University-KMU Joint Research Project (\#NSYSU-KMU 106-p001), the Kaohsiung Municipal Ta-Tung Hospital (KMUH105-5R61), and the Health and welfare surcharge of tobacco products, the Ministry of Health and Welfare, Taiwan, Republic of China (MOHW105-TDU-B-212-134007). The authors thank Dr Hans-Uwe Dahms for help with English editing.

\section{Disclosure}

The authors report no conflicts of interest in this work.

\section{References}

1. Warnakulasuriya S. Global epidemiology of oral and oropharyngeal cancer. Oral Oncol. 2009;45(4-5):309-316.

2. Petersen PE. Oral cancer prevention and control - the approach of the World Health Organization. Oral Oncol. 2009;45(4-5):454-460.

3. Hager S, Ackermann CJ, Joerger M, Gillessen S, Omlin A. Anti-tumour activity of platinum compounds in advanced prostate cancer-a systematic literature review. Ann Oncol. 2016;27(6):975-984.

4. Sithranga Boopathy N, Kathiresan K. Anticancer drugs from marine flora: an overview. J Oncol. 2010;2010:214186.

5. Lee JC, Hou MF, Huang HW, et al. Marine algal natural products with anti-oxidative, anti-inflammatory, and anti-cancer properties. Cancer Cell Int. 2013;13(1):55.

6. Kim JK, Kang KA, Piao MJ, et al. Generation of reactive oxygen species and endoplasmic reticulum stress by Dictyopteris undulata extract leads to apoptosis in human melanoma cells. J Environ Pathol Toxicol Oncol. 2015;34(3):191-200.

7. Han Y, Cui Z, Li YH, Hsu WH, Lee BH. In vitro and in vivo anticancer activity of pardaxin against proliferation and growth of oral squamous cell carcinoma. Mar Drugs. 2016;14(1):2.

8. Yeh CC, Yang JI, Lee JC, et al. Anti-proliferative effect of methanolic extract of Gracilaria tenuistipitata on oral cancer cells involves apoptosis, DNA damage, and oxidative stress. BMC Complement Altern Med. 2012;12(1): 142 .

9. Shin YS, Cha HY, Lee BS, et al. Anti-cancer effect of luminacin, a marine microbial extract, in head and neck squamous cell carcinoma progression via autophagic cell death. Cancer Res Treat. 2016;48(2):738-752.

10. Yen $\mathrm{WH}, \mathrm{Hu} \mathrm{LC}, \mathrm{Su} J \mathrm{H}$, et al. Norcembranoidal diterpenes from a Formosan soft coral Sinularia sp. Molecules. 2012;17(12):14058-14066.

11. Lin YY, Lin SC, Feng CW, et al. Anti-inflammatory and analgesic effects of the marine-derived compound excavatolide B isolated from the culture-type Formosan Gorgonian Briareum excavatum. Mar Drugs. 2015;13(5):2559-2579.

12. el Sayed KA, Hamann MT. A new norcembranoid dimer from the red sea soft coral Sinularia gardineri. J Nat Prod. 1996;59(7):687-689.

13. Takaki H, Koganemaru R, Iwakawa Y, Higuchi R, Miyamoto T. Inhibitory effect of norditerpenes on LPS-induced TNF-alpha production from the Okinawan soft coral, Sinularia sp. Biol Pharm Bull. 2003; 26(3):380-382. 
14. Liang CH, Wang GH, Chou TH, et al. 5-epi-Sinuleptolide induces cell cycle arrest and apoptosis through tumor necrosis factor/ mitochondria-mediated caspase signaling pathway in human skin cancer cells. Biochim Biophys Acta. 2012;1820(7):1149-1157.

15. Shoji N, Umeyama A, Arihara S. A novel norditerpenoid from the Okinawan soft coral Sinularia sp. J Nat Prod. 1993;56(9):1651-1653.

16. Ahmed AF, Shiue RT, Wang GH, Dai CF, Kuo YH, Sheu JH. Five novel norcembranoids from Sinularia leptoclados and S. parva. Tetrahedron. 2003;59(8):7337-7344.

17. Tseng YJ, Ahmed AF, Dai CF, Chiang MY, Sheu JH. Sinulochmodins A-C, three novel terpenoids from the soft coral Sinularia lochmodes. Org Lett. 2005;7(17):3813-3816.

18. Chang YT, Huang CY, Li KT, et al. Sinuleptolide inhibits proliferation of oral cancer Ca9-22 cells involving apoptosis, oxidative stress, and DNA damage. Arch Oral Biol. 2016;66:147-154.

19. Gibson KR, Neilson IL, Barrett F, et al. Evaluation of the antioxidant properties of $\mathrm{N}$-acetylcysteine in human platelets: prerequisite for bioconversion to glutathione for antioxidant and antiplatelet activity. J Cardiovasc Pharmacol. 2009;54(4):319-326.

20. Chang HS, Tang JY, Yen CY, et al. Antiproliferation of Cryptocarya concinna-derived cryptocaryone against oral cancer cells involving apoptosis, oxidative stress, and DNA damage. BMC Complement Altern Med. 2016;16(1):94.

21. Chen CY, Yen CY, Wang HR, et al. Tenuifolide B from Cinnamomum tenuifolium stem selectively inhibits proliferation of oral cancer cells via apoptosis, ROS generation, mitochondrial depolarization, and DNA damage. Toxins (Basel). 2016;8(11):319.

22. Shu CW, Chang HT, Wu CS, et al. RelA-mediated BECN1 expression is required for reactive oxygen species-induced autophagy in oral cancer cells exposed to low-power laser irradiation. PLoS One. 2016;11(9): e0160586.

23. Wu CH, Bai LY, Tsai MH, et al. Pharmacological exploitation of the phenothiazine antipsychotics to develop novel antitumor agents-A drug repurposing strategy. Sci Rep. 2016;6:27540.

24. Chiu CC, Haung JW, Chang FR, et al. Golden berry-derived 4betahydroxywithanolide $\mathrm{E}$ for selectively killing oral cancer cells by generating ROS, DNA damage, and apoptotic pathways. PLoS One. 2013; 8(5):e64739

25. Yen YH, Farooqi AA, Li KT, et al. Methanolic extracts of Solieria robusta inhibits proliferation of oral cancer $\mathrm{Ca} 9-22$ cells via apoptosis and oxidative stress. Molecules. 2014;19(11):18721-18732.

26. Chan WH, Wu HJ, Hsuuw YD. Curcumin inhibits ROS formation and apoptosis in methylglyoxal-treated human hepatoma G2 cells. Ann $N$ Y Acad Sci. 2005;1042:372-378.

27. Carter WO, Narayanan PK, Robinson JP. Intracellular hydrogen peroxide and superoxide anion detection in endothelial cells. J Leukoc Biol. 1994;55(2):253-258.

28. Mukhopadhyay P, Rajesh M, Yoshihiro K, Hasko G, Pacher P. Simple quantitative detection of mitochondrial superoxide production in live cells. Biochem Biophys Res Commun. 2007;358(1):203-208.

29. Hseu YC, Lee MS, Wu CR, et al. The chalcone flavokawain B induces G2/M cell-cycle arrest and apoptosis in human oral carcinoma HSC-3 cells through the intracellular ROS generation and downregulation of the Akt/p38 MAPK signaling pathway. J Agric Food Chem. 2012; 60(9):2385-2397.

30. Shih HC, El-Shazly M, Juan YS, et al. Cracking the cytotoxicity code: apoptotic induction of 10 -acetylirciformonin B is mediated through ROS generation and mitochondrial dysfunction. Mar Drugs. 2014; 12(5):3072-3090.

31. Samhan-Arias AK, Martin-Romero FJ, Gutierrez-Merino C. Kaempferol blocks oxidative stress in cerebellar granule cells and reveals a key role for reactive oxygen species production at the plasma membrane in the commitment to apoptosis. Free Radic Biol Med. 2004;37(1):48-61.

32. Oh SH, Lim SC. A rapid and transient ROS generation by cadmium triggers apoptosis via caspase-dependent pathway in HepG2 cells and this is inhibited through $N$-acetylcysteine-mediated catalase upregulation. Toxicol Appl Pharmacol. 2006;212(3):212-223.
33. Li JJ, Tang Q, Li Y, et al. Role of oxidative stress in the apoptosis of hepatocellular carcinoma induced by combination of arsenic trioxide and ascorbic acid. Acta Pharmacol Sin. 2006;27(8):1078-1084.

34. Ehlers RA, Hernandez A, Bloemendal LS, Ethridge RT, Farrow B, Evers BM. Mitochondrial DNA damage and altered membrane potential (delta psi) in pancreatic acinar cells induced by reactive oxygen species. Surgery. 1999;126(2):148-155.

35. Aruoma OI, Halliwell B, Hoey BM, Butler J. The antioxidant action of $\mathrm{N}$-acetylcysteine: its reaction with hydrogen peroxide, hydroxyl radical, superoxide, and hypochlorous acid. Free Radic Biol Med. 1989; 6(6):593-597.

36. Atalay F, Odabasoglu F, Halici M, et al. $N$-acetyl cysteine has both gastro-protective and anti-inflammatory effects in experimental rat models: its gastro-protective effect is related to its in vivo and in vitro antioxidant properties. J Cell Biochem. 2016;117(2):308-319.

37. Lasram MM, Lamine AJ, Dhouib IB, et al. Antioxidant and anti-inflammatory effects of $\mathrm{N}$-acetylcysteine against malathioninduced liver damages and immunotoxicity in rats. Life Sci. 2014; 107(1-2):50-58.

38. Sadowska AM, Manuel YKB, De Backer WA. Antioxidant and antiinflammatory efficacy of NAC in the treatment of COPD: discordant in vitro and in vivo dose-effects: a review. Pulm Pharmacol Ther. 2007; 20(1):9-22.

39. Mukhopadhyay P, Rajesh M, Hasko G, Hawkins BJ, Madesh M, Pacher P. Simultaneous detection of apoptosis and mitochondrial superoxide production in live cells by flow cytometry and confocal microscopy. Nat Protoc. 2007;2(9):2295-2301.

40. Sena LA, Chandel NS. Physiological roles of mitochondrial reactive oxygen species. Mol Cell. 2012;48(2):158-167.

41. Schaar CE, Dues DJ, Spielbauer KK, et al. Mitochondrial and cytoplasmic ROS have opposing effects on lifespan. PLoS Genet. 2015; 11(2):e1004972.

42. He Z, Simon HU. A novel link between p53 and ROS. Cell Cycle. 2013;12(2):201-202.

43. Imai Y, Ohnishi K, Yasumoto J, et al. Glycerol enhances radiosensitivity in a human oral squamous cell carcinoma cell line (Ca9-22) bearing a mutant p53 gene via Bax-mediated induction of apoptosis. Oral Oncol. 2005;41(6):631-636.

44. Kaneda Y, Shimamoto H, Matsumura K, et al. Role of caspase 8 as a determinant in chemosensitivity of p53-mutated head and neck squamous cell carcinoma cell lines. J Med Dent Sci. 2006;53(1):57-66.

45. Yasumoto J, Kirita T, Takahashi A, et al. Apoptosis-related gene expression after hyperthermia in human tongue squamous cell carcinoma cells harboring wild-type or mutated-type p53. Cancer Lett. 2004;204(1):41-51.

46. Ahmad T, Aggarwal K, Pattnaik B, et al. Computational classification of mitochondrial shapes reflects stress and redox state. Cell Death Dis. 2013;4:e461.

47. Orrenius S. Mechanisms of Oxidative Cell Damage. Basel, Switzerland: Birkhäuser Verlag; 1993.

48. Farooqi AA, Li KT, Fayyaz S, et al. Anticancer drugs for the modulation of endoplasmic reticulum stress and oxidative stress. Tumour Biol. 2015;36(8):5743-5752.

49. Kim JK, Kang KA, Ryu YS, et al. Induction of endoplasmic reticulum stress via reactive oxygen species mediated by luteolin in melanoma cells. Anticancer Res. 2016;36(5):2281-2289.

50. Farooqi AA, Fayyaz S, Hou MF, Li KT, Tang JY, Chang HW. Reactive oxygen species and autophagy modulation in non-marine drugs and marine drugs. Mar Drugs. 2014;12(11):5408-5424.

51. Zafarullah M, Li WQ, Sylvester J, Ahmad M. Molecular mechanisms of $N$-acetylcysteine actions. Cell Mol Life Sci. 2003;60(1):6-20. 
OncoTargets and Therapy

\section{Publish your work in this journal}

OncoTargets and Therapy is an international, peer-reviewed, open access journal focusing on the pathological basis of all cancers, potential targets for therapy and treatment protocols employed to improve the management of cancer patients. The journal also focuses on the impact of management programs and new therapeutic agents and protocols on

patient perspectives such as quality of life, adherence and satisfaction The manuscript management system is completely online and includes a very quick and fair peer-review system, which is all easy to use. Visit http://www.dovepress.com/testimonials.php to read real quotes from published authors.

Submit your manuscript here: http://www.dovepress.com/oncotargets-and-therapy-journal 